\title{
Os dilemas do financiamento político: lições para o caso brasileiro
}

Rodolfo Marcílio Teixeira*

\section{Resumo}

As discussões sobre a reforma do financiamento político no Brasil têm destaque periódico na mídia. No entanto, o senso comum a respeito do tema apresenta uma perspectiva limitada, sobretudo no caso do eleitorado brasileiro. Este artigo busca auxiliar neste entendimento, apresentando as principais considerações de acordo com a literatura especializada. Para isso, trata dos problemas metodológicos, da sua evolução histórica, das críticas e tendências de reforma no exterior. Ele termina por analisar o caso brasileiro, dando ênfase à questão do financiamento exclusivamente público e apontando que certa dose de ceticismo em relação aos seus benefícios é bastante salutar.

Palavras-chave: eleições, financiamento político, financiamento público, sistemas eleitorais.

\section{Introdução: definição e problemas metodológicos}

$\mathrm{O}$ financiamento político é uma temática controversa para quase todas as democracias contemporâneas. Embora seja ponto pacífico que a competição eleitoral precise ser adequadamente financiada, "há uma enorme dificuldade em praticamente todos os países em regular, através de diferentes limitações e incentivos, a prática de financiamento, evitando riscos e distorções e ao mesmo tempo garantindo condições materiais para a competição democrática" (SPECK, 2005; p.127). Muito embora o tema esteja sendo

Doutor em Sociologia Política pela Universidade de Brasília. Trabalha como Educador Social para a Secretaria de Estado de Desenvolvimento e Transferência de Renda do Governo do Distrito Federal (SEDEST/GDF). Endereço eletrônico: rodolfoteixeira@ yahoo.com.br. 
amplamente discutido, o senso comum a respeito do significado do termo "financiamento político" apresenta uma perspectiva limitada, sobretudo no caso do eleitorado brasileiro. Ao contrário da visão comum, esta temática vai muito além dos recursos econômicos utilizados para financiar os partidos, a classe política e as campanhas eleitorais, tratando também sobre o uso de fundos para o apoio financeiro e midiático a grupos de interesse; o suporte de lobistas engajados; o uso patrimonialista de bens e serviços do Estado ${ }^{1}$, entre outros (CARLSON, 2004, p. 02).

Portanto, devido à multiplicidade de instituições, procedimentos e atores interconectados, é impossível enxergar um panorama detalhado e completo dos valores injetados nos sistemas políticos, tanto através dos canais formais quanto por meios ilegítimos (DUSCHINSKY, 2001). Ademais, o encobrimento das quantias e das trajetórias pelas quais o dinheiro percorre até chegar aos seus destinos finais dificulta o desenvolvimento de estudos comparativos mais aprofundados sobre esta temática, assim como a avaliação da eficiência e eficácia das políticas públicas destinadas à sua regulação.

Ao mesmo tempo, as análises do impacto de novas medidas restritivas precisam ser relativizadas porque, quando determinadas formas de financiamento passam a ser fiscalizadas (ou suprimidas), os recursos ilícitos são desviados por rotas alternativas cuja regulação ainda não existe ou possui fragilidades legais. Dessa forma, tanto os dados sobre os aportes financeiros que circulam na política quanto o impacto de determinadas medidas restritivas precisam ser vislumbrados com bastante cautela.

Motivada pela preocupação em relação à necessidade de novos estudos comparativos mais aprofundados sobre o financiamento político, Scarrow (2007) propõe que comparações entre

\footnotetext{
1 Exemplos dos casos acima citados no Brasil são: ações da Bancada Ruralista e o lobby do setor financeiro; financiamento e divulgação de ações e posições suprapartidárias a respeito do porte de armas, da política de cotas, das pesquisas com células-tronco, dos direitos iguais para os GLBTs etc; custas de processos jurídicos envolvendo partidos e candidatos; utilização da estrutura do congresso para outros fins etc.
} 
diversos países podem ampliar o entendimento sobre as possibilidades e limitações das normas reguladoras. Em contrapartida, Duschinsky (2002) já havia advertido que a falta de confiabilidade nas informações interfere significativamente na análise comparativa do financiamento político. Apesar de ter havido, no decorrer do século XX, um substancial aumento na regulação do financiamento político, a publicação desorganizada e incompleta dos dados pelos órgãos eleitorais, agremiações partidárias, financiadores e candidatos configura-se como um dos principais obstáculo à análise comparativa.

Levando em conta os desafios metodológicos supracitados, o objetivo deste trabalho é aprofundar a discussão sobre os rumos do financiamento político no Brasil, apresentando alguns de seus principais entraves e desafios, à partir de uma revisão da literatura.

\section{Competição eleitoral e reestruturação do financiamento partidário}

De acordo com Hofnung (2008) mesmo depois de várias décadas de emprego do financiamento público direto, em várias democracias a corrupção política ainda sucede em patamares bastante elevados. Apesar disso, afirma que pouco se sabe dos acordos financeiros firmados por candidatos individuais, sobretudo nos países que empregam os modelos de representação proporcional ou mista. Para muitos estudiosos os escândalos provenientes destes acordos são os principais propulsores das alterações nas regras de financiamento político. Mais especificamente, Speck (2005, p. 123) assinala que isto ocorre porque "são poucos os países que não tenham enfrentado escândalos vinculados ao tema do financiamento político, seja em função da suspeita de recursos de origem ilícita, da violação de limites estabelecidos para o financiamento, da prática de doações não registradas ou, em casos mais graves, da suspeita de que as doações estejam vinculadas a favores por parte dos representantes políticos". Na visão de Scarrow (2007), apesar da gravidade destes problemas, regulamentações são comumente adotadas, na grande maioria dos casos, devido à possibilidade de 
fracassos eleitorais que a deterioração da confiança pública nos governantes pode provocar.

Neste contexto, a análise das motivações que levaram a estes escândalos tornou-se algo crucial para o avanço no estudo do tema. Dentre as várias as explicações existe, primeiramente, a percepção compartilhada por parte significativa dos atores políticos e especialistas de que o conjunto das despesas eleitorais aumentou substancialmente tendo, como exemplo, a adoção de modelos de campanha baseados em estruturas organizacionais e tecnológicas mais avançadas e onerosas que exigem o assessoramento de profissionais caros como analistas políticos, lobistas, advogados, equipes de produção audiovisual, entre outros. Ademais, a intensa utilização dos meios de comunicação de massa tornou-se um imperativo que envolve receitas consideráveis (DUSCHINSKY, 2002).

Em contrapartida, os recursos em volume expressivo que faziam parte do modelo tradicional de financiamento partidário, advindo das contribuições financeiras de seus filiados, tem decrescido em razão da desilusão geral com as instituições políticas. Em razão das alterações no perfil das despesas e do encarecimento da atividade política em sua totalidade, os partidos precisaram recorrer a modelos de financiamento que geram maior volume de receita. Em consequiência, as estruturas partidárias também precisaram se reorganizar em face da nova realidade, implicando em mudanças na quantidade e perfil de seus participantes, assim como no posicionamento das legendas no espectro ideológico (DALTON \& WELDON, 2005).

Seguindo esta perspectiva, o tradicional "partido de massa" do início do século XX, que dependia do apoio financeiro maciço de um grande contingente de membros, tornou-se insustentável (HOPKIN, 2004, p. 08-16). Neste novo contexto de financiamento da atividade política, a busca por cargos passa a ser o novo objetivo principal, em detrimento da defesa de políticas públicas específicas. Os partidos então desenvolvem estratégias que podem ser utilizadas conjuntamente para atenuar o problema da escassez de recursos e também mantê-los no jogo. 
O partido "clientelista de massa" atua explorando os recursos da burocracia estatal e trocando favores, estratégia largamente adotada na América Latina (GEDDES, 1994). ${ }^{2}$ Os partidos "elitistas" optam por modelos de financiamento externo e/ou interno. Externamente, o partido "vende" seu apoio em troca da contribuição financeira de indivíduos ou grupos interessados na implementação/revogação de determinada política pública. Internamente, caso bem menos comum, um grupo ou subgrupo de políticos e membros utiliza recursos próprios para garantir que seus interesses privados sejam bem sucedidos. ${ }^{3}$ Finalmente, tem-se o modelo de partido "cartelizado", estratégia que ganhou força sobretudo na Europa Ocidental, que depende essencialmente do financiamento público. Neste caso, o Estado garante a todas as legendas que compõem o sistema político uma fatia do orçamento público, sendo que a maior parte da receita advém da repartição de recursos públicos com base no resultado eleitoral pregresso. Esta forma segura de obtenção de receita permuta a dependência em relação aos membros e grandes doadores pela dependência em relação ao Estado (HOPKIN, 2004, p. 08-16). Vale ressaltar novamente que os partidos que compõem atualmente as democracias ocidentais utilizam, simultaneamente, mais de um dos modelos supracitados.

\section{Reorganização do financiamento político}

Em razão das mudanças na competição eleitoral e procurando atenuar os efeitos nocivos da influência crescente do dinheiro e da desilusão generalizada para com as instituições políticas, diversos países adotaram novas regras de financiamento político mais

2 Alocação em funções estatais e benefícios públicos entre outros. Os pré-requisitos que favorecem a adoção desta estratégia são uma burocracia estatal subdesenvolvida e suscetível a infiltração partidária e elevados gastos públicos com a maquina estatal.

3 De acordo com Hopkin (2004), o caso mais comum é do partido Forza Itália, comandado por Silvio Berlusconi, que empregou substanciais recursos de comunicação, financeiros e humanos de empresas sob seu controle em favor de seu partido e de seus candidatos. Mais ainda, utilizou sua força política institucionalizada para legalmente atenuar o poder de investigação do judiciário e fortaleceu o seu monopólio sobre os meios de comunicação privados na Itália. 
restritivas (POSADA-CARBÓ, 2008; SPECK, 2005; ZOVATTO, 2005). Entre as mais comuns está a regulamentação sobre a divulgação de despesas e receitas partidárias, exigindo dados mais detalhados sobre a procedência e utilização dos recursos adquiridos ${ }^{4}$ e objetivando a prevenção e supressão da corrupção no sistema político.

Outra regulamentação bastante comum é a imposição de limites para as contribuições e os gastos de campanha. No que diz respeito aos limites para contribuições, estes procuram "estabelecer condições mínimas de equidade para a participação dos cidadãos" (SPECK, 2005, p 133). Esta norma impõe limites claros sobre os valores que pessoas físicas e/ou jurídicas podem repassar ao conjunto do sistema político (diretamente aos candidatos, para os partidos políticos ou, especificamente, para as campanhas eleitorais). Em face aos diversos escândalos aos quais suas respectivas classes políticas estiveram sujeitas foram implementadas leis comparativamente mais rigorosas, que suprimem integralmente as contribuições de sindicatos e de pessoas jurídicas do processo eleitoral em diversas democracias, a exemplo da França e Espanha. Quanto aos gastos, normalmente são definidos os limites permitidos aos partidos e candidatos. Eles podem ser mais abrangentes, especificando apenas um patamar máximo para as despesas, ou também podem ser mais detalhados, especificando os valores máximos que podem ser destinados a certos fins A exemplo dos valores destinados à propaganda eleitoral.

Diversos países também desenvolveram regras para a utilização de subsídios públicos diretos para as agremiações partidárias e/ou candidatos. Dependendo do país, estes recursos podem ser empregados livremente ou podem ser destinados, exclusivamente, para fins eleitorais específicos. Seguindo esta lógica, o acréscimo no aporte de subsídios públicos destinados às legendas e candidatos tem sido a alternativa mais adotada para tentar atenuar tanto aumento dos custos, quanto a influência excessiva de grandes doadores nos resultados eleitorais (SCARROW, 2007). Estas verbas

4 Vale lembrar que nem todos os países exigem que todos os itens sejam declarados. 
são distribuídas de acordo com dois modelos básicos. Primeiramente, aquele baseado no princípio da equidade onde os partidos recebem quantidade igual de recursos. $\mathrm{O}$ outro modelo utiliza $\mathrm{o}$ critério de desempenho, de acordo com o sucesso eleitoral em eleições pregressas (SPECK, 2005). Dentre as propostas apontadas, este trabalho se concentra na questão do financiamento público.

\section{Dilemas do financiamento público}

De acordo com seus defensores, o financiamento público possui uma série de características que aprimoram o andamento das eleições. Em primeiro lugar, ele faz com que candidatos em potencial, normalmente desprovidos recursos próprios, tenham reais condições de competirem na arena eleitoral; reduz o peso do dinheiro de origem privada, desobrigando os concorrentes das imposições de seus principais contribuintes; e reduz o tempo gasto pelos candidatos com a arrecadação, liberando-os para tratar de outros aspectos mais importantes do processo político (MAYER et al, 2004). O financiamento público também pode ajudar a reduzir a vantagem na arrecadação que os detentores de cargos têm, ajudando a equilibrar o jogo eleitoral.

Estes recursos também podem auxiliar na divulgação de propostas, sem dependerem da anuência de seus patrocinadores mais abastados. Também ajuda a proteger os partidos considerados mais tradicionais, sobretudo no contexto das democracias recentes que carecem de um sistema partidário consolidado. No mais, o pagamento de subsídios estatais a partidos que estão no governo e na oposição pode fortalecer a competição democrática em bases mais sólidas, uma vez que, no modelo baseado no financiamento privado, somente os partidos que governam se beneficiam dos recursos do Estado (SCARROW, 2007; VAN BIEZEN \& KOPECK'Y, 2007).

Parte da literatura aponta que não existem evidências de que os subsídios sejam responsáveis ou resultantes do declínio da participação partidária formal. Ademais, para estes autores, também não existem evidências de que os subsídios sejam res- 
ponsáveis pela "petrificação" dos sistemas partidários. Também ressalta que existem poucas evidências de que os subsídios públicos inibem o surgimento de novos partidos. (PIERRE et aL, 2000; NASSMACHER \& NASSMACHER, 2001; SCARROW, 2006). Segundo esta linha, apesar da complexidade da discussão, existe por enquanto pouca evidência empírica de que os subsídios públicos causem tanto impacto nas características dos recursos partidários ou no grau de estabilidade do sistema. Dos estudos que encontraram evidências da relação entre subsídios públicos e o tamanho do sistema partidário, a grande maioria trabalha com experiências de um único país (SCARROW, 2007). Em contrapartida, seus próprios estudos comparativos, envolvendo análises de diversos países, não encontraram relação. Neste contexto, aconselha um posicionamento mais prudente e cauteloso sobre os possíveis efeitos negativos dos subsídios públicos , uma vez que muitos outros fatores influenciam a competição política e o exercício de isolar cada um deles ainda não foi elaborado de maneira a fornecer informações concretas que tenham validade para países com diferentes nuances em seus sistemas políticos.

Os especialistas que apoiam a utilização de tais subsídios assinalam que eles conferem mais equilíbrio à competição eleitoral; combatem a corrupção ao exigirem a elaboração compulsória de relatórios detalhados das receitas recebidas e utilizadas; e, no cenário político onde as legendas de pequeno porte (ou recém criadas) têm acesso bastante limitado aos recursos privados, os fundos públicos podem garantir-lhes a sobrevivência. Ademais, recursos públicos podem estimular candidatos qualificados a participar do processo com mais tranquilidade ao conferir-lhes capital suficiente para participar dignamente da disputa, ou pelo menos, com ampla oportunidade de enviar adequadamente sua mensagem aos eleitores; pagar despesas eleitorais impeditivas ${ }^{5}$ que normalmente resultam no desempenho ruim nas pesquisas de opinião; atenuar

5 Exemplos de gastos que podem transformar em barreiras são: a produção áudio-visual seguida de divulgação eleitoral na mídia; a composição de uma equipe política composta por profissionais; o transporte do candidato, entre outros. 
o impacto negativo que fortunas pessoais podem exercer sobre as eleições; ajudar a evitar a compra de influência dentro dos partidos políticos por grupos de interesse ou indivíduos abastados, fortalecendo os primeiros e possibilitando que eles se tornem atores mais responsáveis. (MAYER et al., 2004; SCARROW, 2007).

No que diz respeito à fiscalização, argumenta-se que o financiamento público pode ajudar no controle sobre os custos de campanha e da quantidade de informação à disposição. Na medida em que os candidatos aceitem as subvenções públicas e concordem em respeitar tanto os limites de gastos quanto as normas de divulgação, torna-se possível reduzir a tendência crescente dos gastos da campanha. Ao mesmo tempo, normas de divulgação bem elaboradas podem dar aos eleitores os elementos necessários para uma decisão bem informada, abrindo caminho para um cenário que incentive um comportamento idôneo dos agentes políticos. Dessa forma, a prestação de contas e a divulgação de receitas e despesas podem tornar-se armas eficazes no controle do financiamento político, podendo atenuar, ou até mesmo impedir, eventuais abusos.

Em outras palavras, o predomínio do financiamento privado, além de fragilizar partidos e grupos de interesse menos abastados, resulta em um ambiente propício à corrupção e em um filtro que elimina "candidatos com pouca capacidade de levantar recursos" (SPECK, 2005, p. 140). Este desequilíbrio pode repercutir negativamente tanto na quantidade, quanto na diversidade e na heterogeneidade das alternativas políticas à disposição dos eleitores (MAYER et al., 2004). Ao combater estas mazelas, o financiamento público contribuiria para melhorar o conjunto da competição política, abrindo caminho para um cenário partidário de maior diversificação ideológica e programática.

De modo geral, o estabelecimento de subsídios e regulamentações tornou-se o padrão, variando no grau de rigidez. Apesar das vantagens apresentadas acima, a questão da utilidade do financiamento público está longe do consenso e uma apreciação bem mais detalhada sobre o tema tem descoberto várias fragilidades. São comuns os casos de países que requisitam apenas a divulga- 
ção parcial das subvenções públicas. Em outras situações, apenas um dos receptores (partidos ou candidatos) precisa declarar seus gastos. Além disso, muitos sistemas eleitorais não regulamentam os gastos praticados por grupos de interesse que, embora não estejam disputando cargos, exercem influência direta nos resultados eleitorais. O detalhamento das despesas também varia consideravelmente, assim como o comprometimento dos órgãos de controle em identificar e punir aqueles que descumprirem as determinações (DUSCHINSKY, 2001). Devido à suavidade das punições e ao elevado grau de permissividade, os efeitos esperados com divulgação obrigatória, em muitos casos, não são concretizados.

Como base em argumentos semelhantes, parte significativa da literatura questiona o investimento de recursos públicos em eleições. Muitos advogam que não é possível responder a esta pergunta com segurança porque, conquanto tenham ocorrido progressos, ainda não houve uma avaliação detalhada e abrangente dos sistemas de financiamento político para estabelecer ao certo que alterações chegam aos resultados pretendidos. Mais ainda, "muitos dos argumentos estão embasados em uma quantidade limitada de informações ou, em interpretações pouco confiáveis, baseadas mais em adivinhações do que em evidências sólidas" (MAYER et al., 2004, p. 3). Noutros casos, as análises são propositalmente enviesadas. Em resumo, o apoio ao financiamento público é motivado por aforismos ${ }^{6}$ sobre o processo político que não foram devidamente testados de maneira em estudos comparativos razoavelmente rigorosos. Outros analistas expressam certa preocupação com a crescente dependência dos partidos em relação aos recursos públicos. De modo geral, existe o temor de que as legendas que necessitem demasiadamente destas verbas se afastem cada vez mais de suas bases sociais em nome de um profissionalismo político que, em verdade, se resume a maximização de cargos e de verbas (DUSCHINSKY, 2006; SCARROW, 2007).

6 Foram considerados aforismos os entendimentos de que os custos eleitorais elevados desestimulam a participação no processo eleitoral e que os candidatos a reeleição (detentores de cargos) são, por regra, imbatíveis, entre outros. 
Os críticos do financiamento público também insistem que estes tipos de subsídios podem encorajar a fragmentação partidária. Além disso, podem ajudar a congelar o sistema partidário, uma vez que o cálculo que normalmente define a forma de repasse dos fundos públicos favorece os partidos e candidatos que já são detentores de cargos. $\mathrm{O}$ modelo baseado nos resultados eleitorais anteriores auxilia na perpetuação das forças políticas do momento porque os partidos que obtêm vitórias eleitorais no Legislativo têm consequentemente mais recursos e condições de serem novamente bem sucedidos (SPECK, 2005, p. 144).

Também já foi sugerido que o desejo de congelar o sistema partidário, garantindo que os partidos que já dividem o poder continuem nesta condição é a principal razão para que legendas grandes, com propostas programáticas e ideológicas rivais, colaborem entre si para incorporar os subsídios públicos dentro do sistema político ${ }^{7}$. Esta percepção encontra sustentabilidade na medida em que tanto os pagamentos diretos (recursos depositados em conta corrente pelo Estado) quanto os subsídios indiretos (propaganda eleitoral gratuita, verba de gabinete e auxílios diversos etc.) tendem a ser relativamente proporcionais ao sucesso eleitoral, podendo resultar na proteção do status quo. Por esta razão, a introdução e aumento do financiamento público para os partidos políticos é vista por muitos como uma ameaça tanto à competição política efetivamente democrática, quanto para a alternância de poder, uma vez que protege os detentores de cargos e o cartel de partidos dominantes que objetivam tirar os potenciais novos competidores do páreo.

Finalmente, muito embora novas restrições mais severas possam atenuar a quantidade e volume de transações suspeitas dentro do sistema político, não há garantias que elas conseguirão atingir a meta de mostrar à sociedade que essa subserviência aos

7 A exemplo do caso espanhol, onde PSOE e CDU se apoiaram mutuamente na busca por mais recursos e vantagens no sistema eleitoral, de modo a sobrepujarem seus adversários menos abastados no espectro esquerda-direita. Para o caso da Inglaterra, ver Duschinsky (2006). 
interesses privados inexiste ou é, ao menos, limitada a níveis aceitáveis. Isto porque, entre outras razões, um aumento na quantidade, rigidez e amplitude das regras trarão à tona novos escândalos, fato este que poderá aumentar o sentimento geral de ineficiência do sistema político.

\section{Financiamento político: dilemas jurídicos e reformas}

Um dos principais dilemas jurídicos do financiamento político consiste em que, se as regras exigem pouco dos atores, perdem importância e função. Por outro lado, se elas são excessivamente rígidas, podem paralisar o sistema. Portanto, uma reforma deve tomar os devidos cuidados para não restringir a alternância de poder ou "criminalizar" a política. Neste contexto, o anseio de punir pode resultar na deterioração do arcabouço legal (ZOVATTO, 2005). Na mesma linha, a proposição de uma penalidade tão severa quanto suspender os direitos de um partido de grande porte, e que se encontra no poder, tem um efeito político tão poderoso e devastador, que dificilmente será implementada. A esse respeito, a literatura especializada tem identificado erros grosseiros que demonstram um elevado grau de inefetividade de diversas normas. Exemplificando, os relatórios das legendas francesas já foram considerados por especialistas "trabalhos de ficção"; a averiguação do caso italiano apontou que "uma divulgação honesta" dos recursos utilizados por partidos e candidatos "raramente acontece"; na Inglaterra, a análise dos gastos de campanha para o Legislativo apontou que "o abuso em alguns casos é 'de parar o fôlego"'; nos Estados Unidos, as regras para a divulgação também foram consideradas "uma piada" (DUSCHINSKY, 2001, p. 17-19) .

Uma outra característica comum da maioria absoluta das democracias consiste em que as leis sobre a divulgação de receitas e

8 Tradução própria de frases retiradas de (DUSCHINSKY, 2001; p 16-17). Para o caso francês, este autor cita Doublet (1999; p. 76); para o italiano, Bianco \& Gardini, (1999; p. 28); para o inglês, Committee on Standards in Public Life (1998, II; p. 159); e para os EUA, Drew (1983; p. 2). 
despesas são burladas frequentemente porque se aplicam somente a uma parcela muito pequena das receitas e despesas políticas, independentemente da quantidade de financiamento público e privado inerente a cada sistema político. Para atenuarem este problema de maneira efetiva, estas leis precisam abranger dados mais amplos dos partidos, incluindo os custos financeiros das prévias eleitorais e de outras campanhas internas como a eleição de lideranças (HOFNUNG, 2008). A fiscalização também precisa abarcar a grande variedade de empréstimos e serviços voluntários; as atividades políticas de organizações religiosas e a atuação de fundações e grupos de interesse ${ }^{9}$ que participam direta ou indiretamente do processo político.

Criar um arcabouço jurídico que abarque todas estas áreas não é tarefa fácil. Ao contrário, a "praticidade da inclusão de todas estas atividades dentro do escopo de regras sobre divulgação de receitas e gastos políticos é bastante questionável”. Ademais, "experiências tanto de países latino-americanos como de França, Israel, Espanha e Estados Unidos demonstram que a incapacidade de fazer cumprir as normas destrói as boas intenções dos reformadores" (ZOVATTO, 2005, p. 330). Embora esteja claro que as contribuições de campanha são armas que influenciam imensamente a política, elas estão bem longe de serem as únicas. Consequentemente, as restrições serão inefetivas se outras formas de financiamento politicamente relevantes não forem analisadas e devidamente fiscalizadas. Como não é possível fechar todas as portas, é preciso que tanto a sociedade quanto a classe política compreendam sempre que haverá falhas e que o processo de alteração das regras de financiamento político é contínuo e nunca atingirá um estado de plena segurança (DUSCHINSKY, 2002).

Finalmente, é essencial que as entidades responsáveis por impor as regras de financiamento político tenham recursos e pessoal treinado suficientes para desempenhar suas funções de forma minimamente adequada. Seguindo a mesma lógica, exigir um alto

9 Exemplos destas são a Fundação Perseu Abramo (PT) e o Instituto Teutônio Vilela (PSDB). 
volume de informação sem instrumentos e recursos para processá-la adequada e oportunamente não faz sentido (ZOVATTO, 2005). ${ }^{10}$ Logo, para dar conta destas tarefas, é preciso contar com instituições de controle autônomas, livres de pressões políticas e partidárias, que tenham quantidades adequadas de recursos financeiros e de capital humano para exercer uma efetiva fiscalização (DUSCHINSKY, 2001). No mais, "são necessários órgãos públicos independentes e capacitados para cumprir esta tarefa. A autonomia e eficiência dessas instituições dependem, dentre outros elementos, da independência da sua direção e da capacidade profissional e técnica para dar conta da tarefa de fiscalização" (SPECK, 2005, p. 150-151).

No estudo do financiamento político não existem fórmulas mágicas. Ao contrário, o aperfeiçoamento se obtém por aproximações graduais, ao invés de iniciativas de reforma amplas e ambiciosas. Neste sentido, muitas reformas nas regras de financiamento político devem ser combinadas a reformas político-eleitorais, uma vez que seus efeitos têm impacto direto nas formas de organização e administração dos partidos; na competição interna por cargos de chefia dentro das legendas e nas condições gerais da competição eleitoral, afetando também "a própria credibilidade e legitimidade da democracia”. É preciso compreender que, devido às suas características, este é um assunto "condenado à sucessão de distintas reformas legais". Logo, é preciso aceitar o "seu caráter flutuante e conjuntural”. Neste contexto, reformas políticas costumam produzir resultados indesejados que devem ser retificados através de outras reformas (ZOVATTO, 2005, p. 327) ${ }^{11}$.

Na mesma linha, mudanças na legislação não deveriam ser meros exercícios de realização de desejos imponderados de políticos afoitos e atores frequentemente mal intencionados. A criação

10 As instituições de fiscalização e controle são consideradas por Zovatto (2005) o aspecto mais frágil dos sistemas de financiamento político na maioria dos países da América Latina.

11 Não por acaso, este autor cita González-Varaz (1995, p. 203) para afirmar que a reforma do financiamento eleitoral na Alemanha é chamada de "legislação interminável", devido ao seu destaque nos últimos 50 anos. 
leis incita os atores envolvidos a procurar e encontrar outras brechas no sistema, assim demandando novas alterações na legislação. Comprovações deste padrão podem ser encontradas na quantidade de "aperfeiçoamentos de reformas" que foram instauradas na França, Estados Unidos, Itália e Alemanha. Estes são alguns dos muitos exemplos de casos onde a introdução de novas regras para o financiamento político produziu efeitos inesperados ou até mesmo contrários. O tempo curto para analisar, votar e aplicar estas modificações antes da próxima eleição - situação que acontece corriqueiramente nos processos de reforma política - produz frequentemente uma legislação controversa e marcada por interesses contraditórios (DUCHINSKY, 2001) ${ }^{12}$.

Também vale ressaltar que, apesar do que pensa parte significativa da classe política brasileira, é bastante improvável que o estudo comparativo dos diversos sistemas de financiamento existentes desvende algum tipo de instrumental universalmente aplicável (SCARROW, 2007, p. 207). Portanto, é preciso ter em mente existem "tradeoffs" que beneficiam e priorizam determinados princípios e grupos de interesse, em detrimento de outros (CARLSON, 2004). Como existe uma relação bastante particular entre o financiamento político e o sistema partidário, também existe outra importante ligação - indissolúvel - entre o sistema político e a cultura de cada país (ZOVATTO, 2005). Sendo assim, o impacto de alterações teoricamente similares tende a produzir resultados diversos em diferentes países. Consequentemente, o mesmo aparato legal pode ser bem sucedido ou fracassar em realidades distintas. Portanto, os autores acima concordam que não existe um modelo de financiamento que seja adaptável e operacional em todos os países. Ao contrário, cada um precisa criar e aplicar um sistema próprio, em concordância com seus valores políticos e sua cultura, seu sistema político e eleitoral, sua capacidade institucional e, em

12 Duchinsky (2001, p. 18-19) cita Nassmacher (1993, p. 260). Este último ressalta que restrições designadas para o controle do fluxo de dinheiro no processo político encorajaram os políticos na busca por fragilidades na aplicação da lei ou na costura de emendas. 
geral, com o grau de desenvolvimento de sua democracia. Os resultados vão depender, em grande medida, da tradição histórica e dos recursos disponíveis em cada sociedade.

\section{Financiamento político: o caso do Brasil}

Na década de 1990, a necessidade de amplas mudanças no sistema político brasileiro culminou na concepção da Lei de Partidos Políticos ${ }^{13}$ e na Lei Eleitoral. ${ }^{14}$ Apesar da maior rigidez imposta, o comportamento destes atores permaneceu sob desconfiança, sobretudo no que diz respeito aos recursos não inclú́dos na prestação de contas. Outros indícios incluem receitas ilícitas advindas do crime organizado e de entidades beneficiadas pela aquisição de contratos públicos.

Além dos problemas acima descritos, o modelo brasileiro de financiamento político não busca estabelecer um maior grau de equidade. Os limites estabelecidos para pessoas físicas e jurídicas são, respectivamente, de $10 \%$ da renda e $2 \%$ do faturamento no ano anterior. Neste contexto, aqueles que possuem mais recursos disponíveis podem influenciar mais significativamente no processo, através de contribuições mais robustas. Assim, "uma fração ínfima do eleitorado contribui para campanhas eleitorais de algum candidato". Em oposição, pessoas jurídicas contribuem com quase $60 \%$ das doações destinadas aos candidatos à Câmara Federal. Isto demonstra "o papel preponderante do poder econômico no financiamento eleitoral" (SPECK, 2005, p. 149). No que diz respeito ao financiamento público, a maior fatia destes recursos é distribuída de acordo com os resultados da eleição anterior para a Câmara Federal. ${ }^{15}$ Mais ainda, existe "uma dependência unilateral do candidato dos seus principais financiadores. Grande parte dos candidatos a deputado federal depende exclusivamente de recursos de

13 Lei 9.096 dos Partidos Políticos, 19 de setembro de 1995.

14 Lei 9.504 de Normas para as Eleições, 30 de setembro de 1997.

15 De acordo com Speck (op. cit.; página 146), 99\% do fundo partidário e 2/3 do horário eleitoral são distribuídos de acordo com o sucesso eleitoral. Trechos retirados das páginas 136 a 146. 
um único doador. Para $23 \%$, o principal doador contribui mais da metade dos recursos" (SPECK, 2005, p. 149).

Na tentativa de eliminar esta condição de dependência, foram elaborados vários projetos de lei com propostas diferentes de financiamento público exclusivo. Basicamente, todas as propostas vedam o aporte de pessoas físicas e jurídicas. Como contrapartida, oferecem às legendas uma fatia do financiamento público que resulta (com variações) do peso de cada partido em termos de votos obtidos na eleição anterior. A grande maioria ficou pelo caminho devido a erros na sua elaboração, discordâncias metodológicas ou pela falta de interesse partidário. No entanto, a proposta contida nos Projetos de Lei 2679/03 e 1210/07 conseguiu ir adiante e serviu como base para as propostas que devem seguir para apreciação no ano de 2011.

Os projetos de lei citados modificam significativamente a estrutura do aparato político-institucional brasileiro. Para dar sustentabilidade ao esquema de financiamento público (exclusivo) que viabiliza o modelo de partido de cartel, estes projetos também alteram o sistema proporcional para eleições legislativas ao permutar a lista aberta pelo padrão de lista fechada e preordenada pelas próprias agremiações; propõem o fim das coligações partidárias para as eleições proporcionais, mantendo-as apenas para os pleitos majoritários; e estabelecem cláusulas de barreira, dentre outras mudanças. Ademais, tentam garantir a boa utilização dos recursos públicos ao criarem normas para distribuição destas receitas dentro dos partidos, de acordo com os cargos cobiçados.

De acordo com o Projeto de Lei 2679/03, proporcionalmente, o financiamento exclusivamente público levaria a um acréscimo significativo nas receitas, passando de 120 milhões em 2006, para algo entre 850 e 966 milhões de reais em 2010. A utilização deste instrumento pode tornar a participação política mais igualitária, na medida em que - com a exclusão do financiamento privado - o único aspecto em disputa seria o voto. Também tornaria a competição eleitoral mais justa porque as verbas seriam divididas de acordo com critérios pré-definidos e não sujeitaria os políticos às 
pressões dos seus financiadores (FLEISCHER, 2004, p. 89). Como resultante, a Justiça Eleitoral poderia focar na fiscalização das contas das legendas. No entanto, "se bem regulamentado e fiscalizado, o sistema de financiamento 'misto' seria mais adequado - mas com os poderes da Justiça Eleitoral ampliados para fiscalizar, punir, impugnar e cassar candidaturas (...)" (FLEISCHER, 2008, p. 174).

No caso brasileiro, o financiamento exclusivamente público poderia resultar na redução do caixa dois e na organização de eleições mais transparentes. Em contrapartida, embora o apoio estatal exclusivo possa trazer benefícios, também pode distorcer significativamente a competição, além de promover o enfraquecimento do "enraizamento social" devido à proibição do financiamento privado de pequeno porte, o que seria um atraso para do ponto de vista democrático. Além disso, o financiamento exclusivamente público tornaria os partidos completamente dependentes dos recursos estatais. Em última instância, a repartição do financiamento público em proporção similar ao sucesso dos partidos no pleito eleitoral precedente "representa a extrapolação desses resultados para a atual eleição" (SPECK, op. cit.).

De modo geral, esta alteração não garante uma redução significativa do financiamento privado adquirido de forma ilícita, uma vez que não cobre os custos eleitorais. O dinheiro utilizado na eleição de 2002, por exemplo, está próximo de 10 bilhões de reais (FLEISCHER, 2004, p. 89). A maior parte destes recursos é proveniente da utilização de recursos ilícitos de origem privada que objetivam cooptar os políticos em favor de suas causas pessoais. Para piorar, os valores relatados aos órgãos fiscalizadores não atingem um décimo do valor mencionado acima. Dessa forma, é possível deduzir que a demanda reprimida manterá o caixa-dois em pleno funcionamento, até porque as propostas de reforma não alteram o arcabouço institucional de fiscalização e também não impõem um conjunto de punições mais rígidas aos infratores.

Também existe uma questão política mais complexa. Se por um lado haveria uma diminuição no fardo da Justiça Eleitoral devido à redução do número de atores passivos de serem fiscalizados, 
por outro, não há garantias de que esta instituição teria força política ou interesse em punir os partidos com o adequado rigor no advento de irregularidades na prestação de contas.

De fato, as regras que definem as eleições para o legislativo brasileiro encorajam altos custos de campanha ao minimizarem o controle dos partidos sobre os financiamentos e exigirem que os candidatos levantem e utilizem o dinheiro individualmente. Não obstante, é preciso ter cautela sobre a necessidade de mais verbas públicas para tal fim, uma vez que "os partidos políticos e campanhas políticas no Brasil já são custeados publicamente por meio do fundo partidário, das subvenções que os eleitos recebem para empregar pessoas em seus gabinetes e para divulgar seu trabalho, e do horário eleitoral gratuito" (SAMUELS, 2006, p. 148). Portanto, é preciso intensificar a fiscalização para se coibir de forma eficiente o caixa dois, também atentando para os critérios de distribuição do Fundo.

As propostas atualmente em análise no Congresso não respondem diretamente aos problemas e necessidades acima mencionados (SAMUELS, 2006, p. 151). O financiamento público acabaria com o uso disseminado de caixa dois utilizando valores considerados insuficientes? Como os partidos decidirão o gasto dos fundos de campanha? Estes e outros questionamentos não têm resposta por impossibilidade de ocorrência empírica. No entanto, é possível supor que a liderança nacional do partido terá papel dominante sobre esta decisão e, fatalmente, favorecerá determinados candidatos em detrimento de outros. Isto criará, possivelmente, muitos problemas dentro das legendas. Mais ainda, mudará a lógica descentralizada de determinadas campanhas eleitorais permeadas por considerações locais, e não questões nacionais. Noutra vertente, o financiamento público pode ser implementado apenas com o fortalecimento do TSE a partir de uma reestruturação interna, do aumento da verba para fiscalização e punição dos partidos e da adaptação da legislação bancária. Do contrário, será difícil fiscalizar a entrega de recursos às campanhas e fácil burlar leis existentes ou futuras (RIBEIRO, 2006). Em resumo, o financiamento pú- 
blico de campanhas poderá criar mais problemas que resolvê-los.

Não seria um equívoco dizer que a Justiça Eleitoral possui, de modo geral, um histórico geralmente positivo como árbitro da contestação política. Ela também tem se mostrado extremamente eficaz na melhoria do processo eleitoral e na absorção de um eleitorado que cresceu continuamente (TAYLOR, 2006, p. 149). Não obstante, o desempenho da Justiça Eleitoral deixa muito a desejar, avançando pouco no sentido de fiscalizar a participação dos partidos ou dos candidatos nas mesmas eleições, e muito menos ainda na punição de eventuais erros decorrentes da atuação destes atores políticos. Esta instituição encontra muitas dificuldades em fiscalizar, detectar irregularidades e punir os envolvidos em crimes eleitorais, ou seja, no financiamento irregular de campanhas e uso indevido da máquina governamental, entre outros. A esse respeito, apenas $0,3 \%$ das representações resultam em condenação por crime eleitoral (SANTOS, 2003). Este desempenho ocorre devido a reconhecidas "deficiências técnico-materiais e de recursos humanos da Justiça Eleitoral” (SADEK, 1995, p. 67).

Neste sentido, para exercer eficientemente a tarefa de fiscalizar, a Justiça Eleitoral precisa ser fortalecida com maiores dotações orçamentárias e, pela ampliação de sua estrutura fiscalizadora. Além disso, instrumentos precisam ser criados para racionalizar e alocar as verbas de maneira mais adequada. Em 2004, por exemplo, o TSE dispôs de somente cinco funcionários para realizar todo o controle nacional de despesas partidárias. No mesmo período, esta instituição gastou em torno de R\$ 1 milhão para renovar sua frota de carros oficiais (TAYLOR, op. cit., p. 150-151).

Outro problema associado à Justiça Eleitoral consiste na capacidade "legisladora" do TSE. A análise da legislação eleitoral no Brasil desde 1922 demonstra que o Tribunal Superior Eleitoral (TSE) e suas estruturas estaduais (TREs) são agentes institucionais responsáveis por constantes mudanças e novas regras procedimentais. A partir de 1994, vários pleitos foram marcados por uma legislação de contrastes e favorecimentos. Como exemplo, tem-se a aprovação da Emenda Constitucional n. 06, que permite a ree- 
leição de prefeitos, governadores e do Presidente da República, sem a necessidade de desincompatibilização. Além disso, várias omissões foram verificadas na Lei n. 9504/97 (RIBEIRAL, 2003). Como complicador, o critério de anualidade - estabelecido na Lei Eleitoral - é bastante subjetivo, abrindo espaço para a alteração do "jogo político" pelo TSE, depois de ultrapassado o limite de um ano para o pleito. Esta brecha gera instabilidade política, evidenciada no processo de Verticalização das eleições, ocorrido em 2002 (TEIXEIRA, 2004) e pela ficha limpa, aprovada neste ano de 2010.

Devido ao conjunto de problemas e questionamentos mencionados acima, uma certa dose de ceticismo na criação de regras para o financiamento político é muito bem-vinda. Neste contexto, "talvez seja mais adequado pensar em uma sequência escalonada de reformas, para permitir aos atores - candidatos, doadores, mas, principalmente, órgãos fiscalizadores e sociedade - construir em cima de experiências consolidadas e incorporar as novas exigências sucessivamente e com mais eficiência" (SPECK, op. cit., p. 158).

\section{Considerações finais}

Este trabalho procurou apresentar a dimensão do problema mais geral do financiamento político como pano de fundo para o tema mais específico das propostas de financiamento exclusivamente público no Brasil. Para o adequado tratamento da questão, foi apresentada a importância de se dissociar o tema da influência de escândalos de corrupção e da componente emocional que engloba. Existem também problemas conceituais e metodológicos que precisam ser devidamente enfrentados. Primeiramente, o financiamento político envolve muito mais que dinheiro arrecadado pelos partidos e políticos para fins eleitorais. O impacto desses recursos sobre o sistema político vai muito além de resultados eleitorais imediatos e de alterações no sistema partidário. Ele modifica a lógica da representação e a forma de se fazer política, influindo diretamente no futuro de gerações. Sendo assim, não 
pode ser tratado com base em idealismos distanciados da realidade. Outra dificuldade consiste em que a diversidade de sistemas e culturas políticas impacta de maneira diferente sobre sistemas jurídicos estruturalmente similares, dificultando a previsão dos possíveis resultados provocados por reformas.

A apresentação do contexto em que surgiram as novas regras para o financiamento político serviu para o aceite de duas afirmações: primeiramente, que os contextos eleitorais mudaram e que não é mais possível vislumbrar a competição política sem compreender que o processo está mais complexo e custoso. Não há razão para pensar que esta tendência se modifique no futuro próximo, mesmo que combatida. Em segundo lugar, que as alterações na competição eleitoral modificaram o comportamento partidário em nível global, possivelmente em todas as democracias minimamente constituídas. Os partidos de massa do início do Século XX não são mais a realidade da competição política na maioria destes sistemas democráticos consolidados. Ao contrário, outros modelos nasceram das novas circunstâncias, inclusive aqueles financiados em grande proporção pelo Estado e relativamente mais distantes do eleitorado.

Por um lado o financiamento público traz uma série de aprimoramentos ao andamento das eleições, garantindo o fôlego de candidatos menos expressivos, a sobrevivência de partidos de pequeno porte e um relativo equilíbrio do jogo político. Eles também podem auxiliar no combate à corrupção por meio da apresentação compulsória de relatórios sobre a natureza e uso dos recursos. No entanto, os modelos geralmente concebidos apresentam diversas fragilidades, sobretudo no que diz respeito à crescente fragmentação partidária e ao combate do uso ilícito de financiamento privado. No mais, são fortes os argumentos de que o financiamento público pode congelar o sistema partidário e tornar as legendas mais dependentes do Estado e menos afinadas com o seu eleitorado, produzindo comportamentos que contrariam os preceitos democráticos, a exemplo do "estelionato eleitoral". Outros dilemas, de ordem jurídica, provocam sérias dúvidas sobre a razoabilidade, 
a aplicabilidade e a consecução dos objetivos perseguidos pelas normas empregadas no controle do financiamento político no geral e o financiamento público, no particular.

A proposta brasileira combina o financiamento exclusivamente público a um conjunto de normas que disciplinam a distribuição destes recursos entre os partidos e dentro destes. Estas regras buscam atingir os objetivos gerais de legalidade, transparência e equidade já apresentados e, mais especificamente, procuram garantir que as cúpulas partidárias não utilizem tais recursos de forma desequilibrada, beneficiando excessivamente partidários de um estado da federação, uma corrente interna ou determinado candidato (ou cargo) em detrimento de outros.

São pertinentes as dúvidas sobre se estes objetivos gerais e específicos são factíveis. A adoção de uma regra financiamento público limitado já implica razoável dose de responsabilidade dos governos, uma vez que os mesmos passam a transferir para a arena política verbas que poderiam ser utilizadas para outros fins bem menos controversos. A norma do financiamento exclusivamente público aumenta essa responsabilidade, uma vez que multiplica a quantidade de recursos públicos redirecionados para estes fins e reduz a capacidade dos cidadãos de influenciar o processo político. Não está claro se vale a pena aceitar essa responsabilidade e risco em nome de objetivos cuja consecução é permeada por muitas incertezas.

Ademais, o Brasil é exemplo de excesso de regulamentação e pouca aplicação. É possível questionar se neste caso será diferente, principalmente porque os principais grupos atingidos são a classe política e o empresariado, notórios especialistas em flexibilizar e descumprir leis. Muito embora seja interessante garantir que os subsídios públicos não sejam monopolizados pelas oligarquias, regras muito rígidas para a utilização destes recursos podem engessar os partidos. Ao contrário, estes últimos devem ter espaço para alocar suas receitas de acordo com objetivos cujos critérios de importância são definidos internamente. Esta lógica está implícita no Artigo 17 da Constituição, que assegura às legen- 


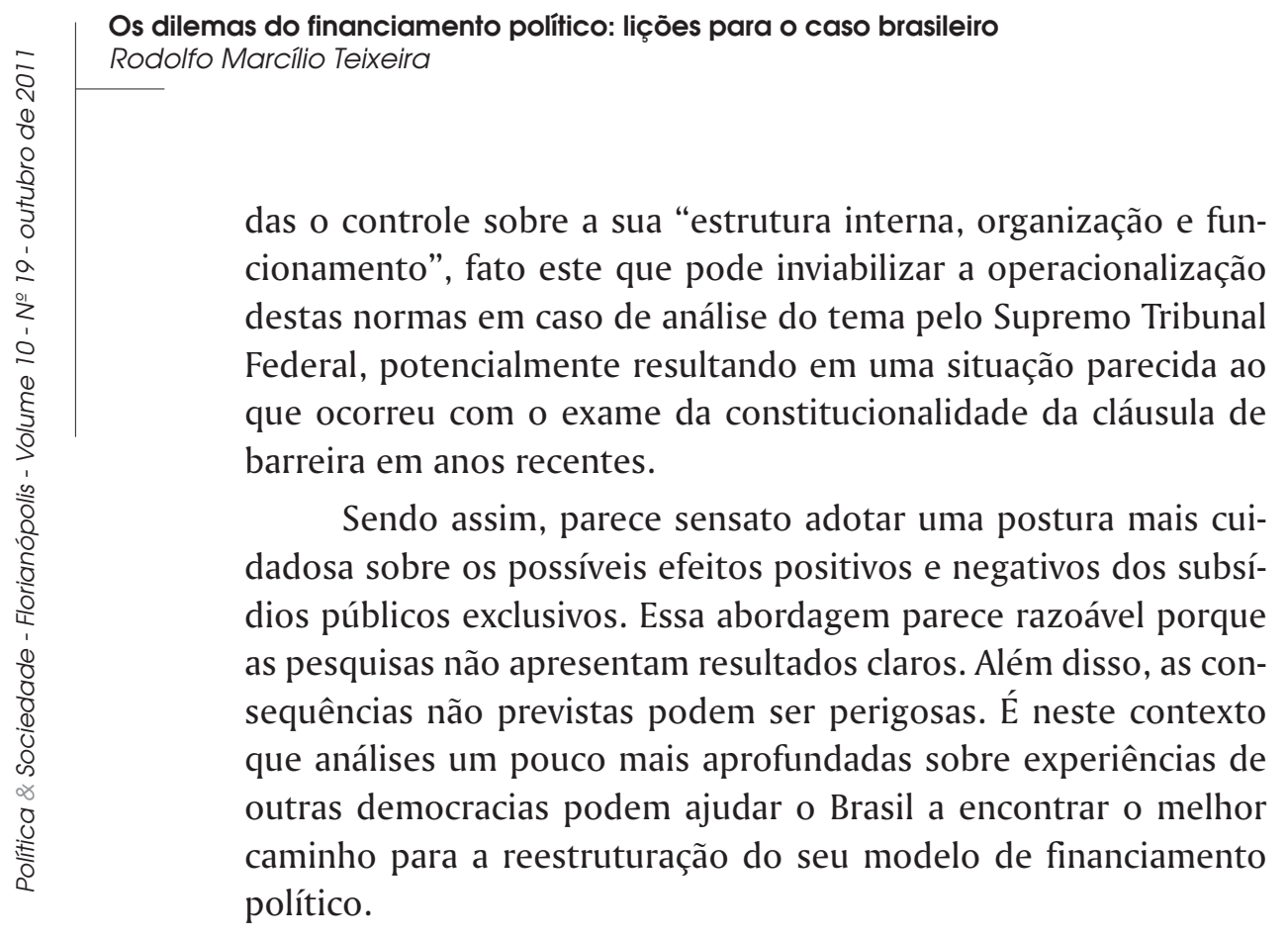

Recebido em: 31.05.2010

Aprovado em: 25.05.2011

\section{Referências}

CARLSON, J. From discourse to action: avoiding pitfalls in political finance disclosure initiatives. IFES Political Finance White Paper Series, IV/Report, 2004. Disponível em: http://moneyandpolitics. net/researchpubs/pdf/discourse_action.pdf.

DALTON, R.; WELDON, S. Public images of political parties: a necessary evil? West European Politics, vol. 28, p. 931-51, 2005.

DUSCHINSKY, M. Political finance and democracy: major challenges for reformers and scholars. Conference "The use and abuse of money in campaigns and elections", June 28-30, 2001, Seoul, South Korea. Anais. Sejong Institute, Sungnam, Korea, and the National Endowment for Democracy, Washington, D.C., U.S.A on Political Finance and Democracy in East Asia. 
Financing Politics: a Global View. Journal of Democracy, Volume 13, n. 4, p. 69-86, Oct. 2002.

It's their party, and we pay for it. The Sunday Times. Oct. 22, 2006. Disponível em: http://www.timesonline.co.uk/tol/ comment/ article608907.ece. Acessado em 15/05/2008.

FLEISCHER, D. Reforma política en Brasil: una historia sin fin. América Latina Hoy, Ediciones Universidad de Salamanca, n. 37, p. 81-99, 2004.

- Reforma política no Brasil: os partidos políticos em questão. In: MULHOLLAND, T.; RENNÓ JUNIOR, L.R. (Org.). Reforma Política em Questão. Brasília: Editora Universidade de Brasília, 2008, v. 1, p. 153-161.

GEDDES, B. Politician's dilemma: building state capacity in Latin America. Berkeley: University of California Press, 1994.

HOFNUNG, M. Unaccounted Competition: The Finance of IntraParty Elections. Party Politics, Sage Publications, vol 14, n.6, p. 726-744, 2008.

HOPKIN, J. The Problem with Party Finance: Theoretical Perspectives on the Funding of Party Politics. Party Politics, vol. 10, n. 6, p. 627651, 2004.

MAYER, K.; WERNER, T.; WILLIAMS, A. Do public funding programs enhance electoral competition? Fourth Annual Conference on State Politics and Policy Laboratories of Democracy. Paper online. Kent State University, Public Policy in the American States, April 30-May 1, 2004.

NASSMACHER, H.; E NASMACHER, K.H. Major impacts of political finance regimes. In: NASSMACHER, K.H. Foundations for Democracy: approaches to comparative political finance. BadenBaden: Nomos, 2001.

PIERRE, J.; SVSAND, L.; WIDFELDT, A. State subsidies to political parties: confronting rhetoric with reality. West European Politics, volume 23, Issue 3, p. 01-24, July 2000. 
POSADA-CARBÓ, E. Democracy, parties and political finance in Latin America. Working Paper, n. 346, University of Notre Dame Press: Kellogg Institute of International Studies, April 2008. Disponível em: http://kellogg.nd.edu/publications/ workingpapers/ WPS/346.pdf. Artigo apresentado à Conference on political finance and demcoracy, Seul, Coreia do Sul, 28 a 30 de junho, 2001.

RIBEIRAL, T. Padrões de competitividade no jogo democrático: a legislação eleitoral no Brasil (1822/1997). São Paulo. Dissertação (Mestrado em Ciência Política). Departamento de Ciência Política, Faculdade de Filosofia, Letras e Ciências Humanas, Universidade de São Paulo - USP, 2003.

RIBEIRO, R. Financiamento de Campanhas (público versus privado). In: AVRITZER, L. \& ANASTASIA, F. (Org.). Reforma política no Brasil. Belo Horizonte: Editora UFMG, 2006, p. 77-81.

SADEK M. T. A Justiça Eleitoral e a Consolidação da Democracia no Brasil. São Paulo: Konrad Adenauer Stiftung, 1995.

SAMUELS, D. Financiamento de campanhas no Brasil e propostas de reforma. In: SOARES, G. \& RENNO, L. (Org.). Reforma política: lições da história recente. Rio de Janeiro: Editora FGV, 2006, p. 133-153.

SANTOS, R. dos. Mídia e democracia na Legislação Eleitoral Brasileira. Um levantamento dos mecanismos legislativos de controle e compensação do uso dos meios de comunicação em contextos eleitorais (1974-2000). Anais do XXVI Congresso Anual em Ciência da Comunicação, Belo Horizonte/MG, Núcleo de Políticas e Economia da Comunicação, 02 a 06 de setembro de 2003.

SCARROW, S. Political finance in comparative perspective. Annual Review of Political Science, v.10, p. 193-210, 2007.

SPECK, B. W. Reagir a escândalos ou perseguir ideais? A regulação do financiamento político no Brasil. Cadernos Adenauer, Ano 6, no. 2, p. 123-159, 2005.

SPECK, B. W. O Financiamento de Campanhas Eleitorais. In: AVRITZER, L. \& ANASTASIA, F. (Org.). Reforma política no Brasil. Belo Horizonte: Editora UFMG, 2006, p. 153- 158. 
TAYLOR, M. Justiça Eleitoral. In: AVRITZER, L. \& ANASTASIA, F. (Org.). Reforma política no Brasil. Belo Horizonte: Editora UFMG, 2006. p. 147-152.

VAN BIEZEN, I; KOPECK'Y, P. The State and the Parties Public Funding, Public Regulation and Rent-Seeking in Contemporary Democracies. Party Politics, vol. 13, n. 2, p. 235-254, 2007.

ZOVATTO, D. Financiamento dos partidos e campanhas eleitorais na América Latina: uma análise comparada. Opinião Pública, Campinas, Vol. XI, no 2, p. 287-336, Outubro, 2005.

\section{Abstract}

The dilemmas of political financing: lessons for Brazil

The discussions on the reform of political financing in Brazil have been highlighted in the regular media. However, common sense on the subject presents a limited perspective, especially in the case of the Brazilian electorate. This article seeks to assist in this understanding, showing the main considerations in accordance with the literature. For this, it deals with the methodological problems, the historical evolution, the criticism and reform trends abroad. It ends by analyzing the Brazilian case, emphasizing the issue of exclusively public funding and pointing out that a certain dose of skepticism about its benefits is quite healthy.

Keywords: elections, political financing, public funding, electoral systems. 